\title{
À descoberta de recursos naturais: Uma atividade outdoor com alunos do Ensino Primário
}

\author{
The discovery of natural ReSOURCES: An OUTdOOR aCtIVITY WITH PrimaRy SCHOOL STUdentS
}

\author{
Rosa Branca Tracana, Ana Lopes, Ana Farinha Direito, Maria Eduarda Ferreira

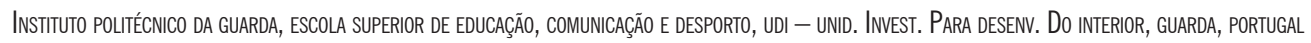 \\ RTRACANA@IPG.PT ANAVENTURA@IPG.PT, ANA.MARTINS45@HOTMALl.COM EROQUE@IPG.PT
}

Abstract:Teaching in context of outdoor-learning is a promising strategy in the development of attitudes and values of respect for nature and its preservation, as well as to raise awareness of the aesthetic aspects of the environment. Natural environment requires that environmental education unleash ecocentric feelings in our children, in order to halt the anthropocentric perspective in relation to the environment. Portuguese primary education presents a curricular guidance for practical outdoor learning in the curriculum, namely discovery of the natural environment, in the fourth year of schooling. So, the aim of this research is to understand if these primary school children knew the natural resource in the local where they live, the River Zêzere, by applying a questionnaire. Face to results obtained we built and validated a teaching resource, a guide, whose purpose is the discovery of this natural resource through an outdoor activity.

\begin{abstract}
Manuscript:
Received: Quadrennial Conference of the International Geoscience Education Organization Accepted: 14/01/2018

Citation:Tracana R.B., Lopes A., Direito A.F., Ferreira M.E. 2018. À descoberta de recursos naturais: Uma atividade outdoor com alunos do Ensino Primário. Terræ Didatica, 14(4):477-486. URL: http://www.ige.unicamp.br/terraedidatica/.
\end{abstract}

Keywords: Environmental Education, Zêzere River, outdoor activity, elementary school.

\section{Introdução}

A inadequada gestão dos recursos naturais e o desrespeito pelo ambiente traduzem-se atualmente em consequências ecológicas graves que, ao interferirem no equilíbrio entre o Homem e a Natureza, tornam a temática da educação ambiental cada vez mais pertinente. Considerada uma área prioritária, a educação ambiental pretende formar uma população mundial consciente e responsável para com o ambiente e os problemas com eles relacionados. $\mathrm{O}$ desenvolvimento de atitudes e valores nas crianças para as questões ambientais implica a procura de práticas pedagógicas motivantes que proporcionem aprendizagens mais significativas. Neste quadro, a formação pedagógica de futuros professores assume, também, particular relevância. Certos da necessidade de enfrentar novos desafios educativos, desenvolvemos este estudo no âmbito do estágio pedagógico habilitador para a docência no ensino primário português (Farinha 2012). O estudo está limitado à área curricular "Estudo do Meio", na qual se integra a educação em ciências e a educação ambiental. É sustentado pela prática da investigação - ação (IA) pois pretende verificar em que medida o trabalho de campo influencia a aquisição de competências sobre o meio ambiente. Assim, o objetivo deste trabalho passou pela valorização da metodologia outdoor learning, nomeadamente as saídas de campo visando tornar as aprendizagens dos alunos mais significativas. Este estudo decorreu no concelho de Celorico da Beira tendo o Rio Zêzere como objeto de estudo. Foram trabalhados os seguintes conteúdos curriculares (DEB 2004): elementos básicos do meio físico local (o solo; a água - distinção dos meios aquáticos existentes na região - cursos de água, oceanos, lagos...-; localização em mapas; identificação de: nascente, foz, margem direita e esquerda e afluentes; os seres vivos do ambiente próximo); poluição de cursos de água (consequências de desequilíbrios ambientais provocados pela atividade humana: extinção de recursos; extinção de espécies animais e vegetais); reservas e parques naturais como meio de preservação do equilíbrio entre a Natureza e a Sociedade. Com o enquadramento exposto, o objetivo deste estudo é proporcionar conhecimentos significativos sobre o ambiente próximo, por meio da descoberta do recurso natural do parque Natural da Serra da Estrela - o rio Zêzere. 
Foi aplicado um questionário para aferir os conhecimentos dos alunos acerca do recurso natural, o rio Zêzere, existente no seu meio envolvente. Face aos resultados obtidos, foi estruturado e validado o guião "Estudo do Rio Zêzere - Fauna e Flora" cuja finalidade é constituir um recurso didático orientador e facilitador de aprendizagens em geociências numa perspetiva ecocêntrica em relação ao meio natural.

Corrobora-se que cada vez mais são necessários espaços físicos, simbólicos, mentais e afetivos diversificados e estimulantes, aulas fora das salas, noutros espaços da escola, do campo, da cidade. Porque o bosque, o museu, o rio, o lago, o meio, bem aproveitados convertem-se em excelentes cenários de aprendizagem (Carbonell 2000).

\section{Marco teórico}

Em educação existem múltiplos caminhos que podem ser utilizados para enriquecer o processo de ensino e aprendizagem e tornar as aprendizagens significativas. Uma das metodologias de ensino a utilizar podem ser as saídas de campo, que assumem particular relevo no que diz respeito aos conteúdos das Geociências contemplados nos Programas curriculares do ensino primário português, nomeadamente na área curricular de "Estudo do Meio". Internacionalmente, em 1946, o Field Studies Council of Britain fundou o primeiro centro com o objetivo de desenvolver o trabalho de campo numa perspetiva educacional. Foi o Movimento da Escola Nova que formalizou e sistematizou uma proposta concreta para que o trabalho de campo figurasse como estratégia pedagógica, quando a área curricular de "Estudo do Meio" passou a ser aceite como importante componente no processo educacional e as atividades de campo ganharam destaque. $\mathrm{Na}$ perspetiva de Palma (2005), a ação educativa só é significativa se coerente, sistemática, contínua e interdisciplinar. Educar nesta perspetiva implica um trabalho de parceria e rentabilização dos recursos locais, uma escola aberta ao exterior, à comunidade e ao meio, sendo que a atividade educativa contextualizada gera aprendizagens significativas e ajuda a desenvolver a consciência ambiental, com hábitos de vida saudável e o exercício da cidadania participativa. Mendes e Rebelo (2011) referem que são trabalhos práticos todas as ações de ensino e aprendizagem que exijam alunos ativamente implicados. Mas este envolvimento ativo dos alunos não se restringe a aspetos de natureza manipula- tiva, como muitas vezes se depreende de algumas propostas mais tradicionais. Ainda na perspetiva de Mendes \& Rebelo (2011) ao mencionarem Leite (2000) e Dourado \& Leite (2008), as atividades práticas podem ser tipificadas em diferentes formatos de trabalho prático: atividades laboratoriais, atividades de campo, atividades experimentais, exercícios de papel e lápis, utilização de um programa informático de simulação, pesquisa de informação em livros, revistas ou internet, realização de entrevistas a membros da comunidade, entre outras.

\section{0 outdoor-learning como estratégia de ensino $\mathrm{e}$ aprendizagem}

Uma das competências gerais a atingir no final do ensino primário obrigatório passa pela capacidade dos alunos em mobilizar saberes culturais, científicos e tecnológicos para compreender a realidade e para abordar situações e problemas do quotidiano (DEB 2004). Para operacionalizar esta competência cabe ao professor, por exemplo, abordar os conteúdos da área do saber com base em situações e problemas; promover intencionalmente, na sala de aula e fora dela, atividades dirigidas à observação e ao questionamento da realidade e à integração de saberes e organizar atividades cooperativas de aprendizagem, orientadas para a integração e a troca de saberes (DEB 2004). Assim, no processo de ensino e aprendizagem a educação ambiental deverá adquirir um lugar de realce e a necessidade de uma abordagem ao nível interdisciplinar. Perspetivando as ideias de Cruz (2007), existem três vetores fundamentais no processo educativo do ensino e aprendizagem: Educação sobre o Ambiente, Educação para o Ambiente e Educação a partir do Ambiente. Continuando a mesma linha de pensamento, no que respeita à Educação para o Ambiente, deseja-se promover a aquisição de valores, atitudes e comportamentos que atuam conjuntamente em defesa e proteção do Ambiente e tudo o que gira em sua volta. Pretende-se que o aluno adquira conhecimentos e capacidades que lhe possibilitem a tomada de decisões atuando de maneira empenhada e com consciência solidária face aos problemas. Finalmente e abordando o último vetor, a Educação a partir do Ambiente, este é duplamente utilizado como recurso educativo. Por um lado, no Ambiente os alunos entram em contato direto com o espaço que lhes proporciona a utilização de processos de observação direta, desenvolvendo um espírito de investigação, com descobertas por si próprios. Por

\begin{tabular}{c|c|c|c|c|c}
\hline (C) Terrae Didat. & Campinas, SP & v.14 & n.3 & p. 477-486 & out./dez. 2018 \\
\hline
\end{tabular}


outro lado, o Ambiente é usado como um autêntico laboratório, onde os alunos desenvolvem as atividades nas várias áreas curriculares aproveitando as oportunidades proporcionadas de forma a serem atingidos os objetivos pretendidos. Cruz (2007) refere que Caride \& Meira (2004) apontam para uma educação ambiental que promova e institua discursos que projetem mudança na sensibilidade e valores que vão orientar a atividade humana em relação com o meio ambiente, dirigida à aquisição de conhecimentos ambientais e uma tomada de consciência critica. De acordo com Morin (1991), os problemas particulares só poderão ser analisados e compreendidos se forem pensados no seu próprio contexto, cada vez mais alargado à escala planetária dada a sociedade de informação em que nos encontramos. Tal desafio traz consigo o da complexidade, pois cada vez mais é reconhecido que as partes estão ligadas entre si. O tipo de experiência a desenvolver fora da sala de aula facilita a aproximação do aluno com o contexto natural e permite uma efetiva relação de proximidade entre ambos. Existem inúmeros estudos que comprovam que as metodologias de ensino e aprendizagem fora dos contextos formais (salas de aula) podem ser potencializadoras de aprendizagens significativas, indo ao encontro das atuais exigências curriculares da educação primária que defendem a supremacia do saber/fazer sobre o saber. É neste contexto que a metodologia outdoor learning assume particular importância. As atividades outdoor concentram-se preferencialmente na promoção da conservação e da proteção ambiental (Bogner \& Wiseman 2004). Segundo Salvador (2007), a atividade outdoor leaning é toda a prática realizada fora da sala de aula, embora não obrigatoriamente realizada em ambiente natural. Assim, as atividades outdoor podem realizar-se em qualquer um dos ambientes de aprendizagem referidos por Orion (2001): ambiente de aprendizagem outdoor (ambiente natural, por exemplo áreas naturais sem intervenção humana); ambiente de aprendizagem outdoor/indoor (ambiente seminatural, por exemplo jardins zoológicos, parques naturais, arredores urbanos, que embora naturais já sofreram intervenção humana) e ambiente de indoor (ambiente construído pelo Homem, por exemplo museus de ciência, centros de ciência e tecnologia indústrias entre outros). Para além dos objetivos pedagógicos e científicos preconizados, estas atividades deverão também promover o desenvolvimento de objetivos sociais, relacionais e afetivos (Fig. 1).

Sintetizando, podemos referir que, as ativi-

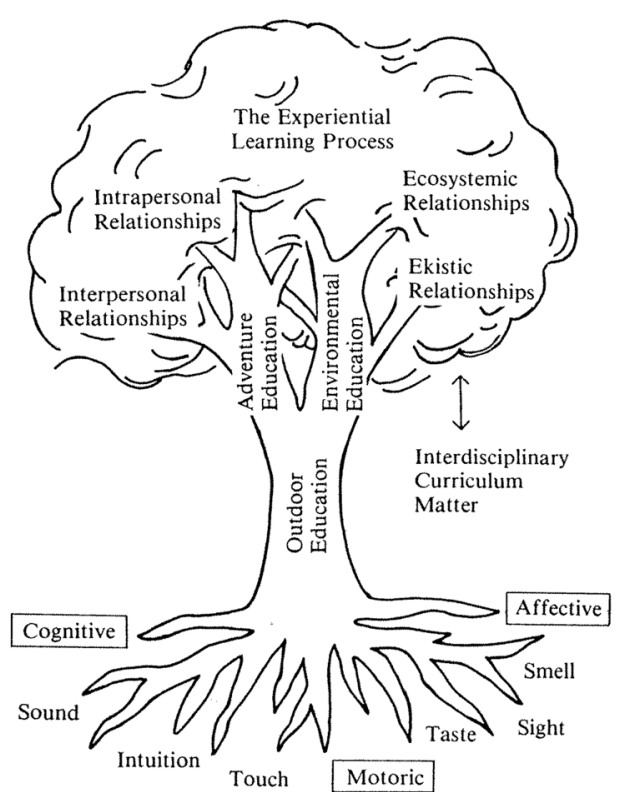

Figura 1. Árvore da Outdoor Education. Fonte: Adaptado de Priest (1986)

dades outdoor, nomeadamente as saídas de campo, permitem o desenvolvimento de um conjunto de competências interdisciplinares relacionadas com a promoção da cidadania e o desenvolvimento do saber-ser. Apoiados na observação direta da realidade, os alunos podem fazer uma releitura critico-construtiva da realidade, identificando os seus problemas socio-ambientais, estabelecer relações entre as informações levantadas, bem como elaborar propostas para a transformação da mesma (Santos 2005). As saídas de campo possibilitam o desenvolvimento de várias competências nomeadamente a aplicação de técnicas de pesquisa, recolha e tratamento de informação, desenvolvimento de capacidades de observação e organização do trabalho, elaboração de sínteses e relatórios; promoção do trabalho em equipa e desenvolvimento do espírito de cooperação e parceria.

De acordo com Morcillo (1998), existem vários tipos de saídas de campo e de acordo com a sua tipologia os guiões são diferentes (Fig. 2).

Existem, assim, diversas etapas obrigatórias que devem ser realizadas antes, durante e após as saídas de campo de modo a transformar esta estratégia numa efetiva aprendizagem para os alunos. A primeira fase consiste na preparação. Esta pretende motivar os alunos estimulando-os para o objeto de estudo e fazendo com que este coloque as primeiras questões de modo informal. É fundamental a motivação dos alunos, contribuindo para isso o conhecimento à priori dos objetivos da atividade 


\begin{tabular}{|c|c|c|}
\hline \multicolumn{2}{|c|}{ Tipo de saída } & Relação Professor-Aluno \\
\hline \multicolumn{2}{|l|}{$\begin{array}{l}\text { Tradicional } \\
\text { Comentada } \\
\text { Dirigida } \\
\text { Descritiva } \\
\text { Guiada } \\
\text { Transmissiva } \\
\text { Excursão geológica }\end{array}$} & $\begin{array}{l}\text { - Ensino expositivo centrado no professor. Os } \\
\text { alunos redescobrem os conceitos e factos que o } \\
\text { professor pretendia desde o princípio. O grau de } \\
\text { participação do aluno reduz-se a tomar } \\
\text { apontamentos e, ocasionalmente, à elaboração } \\
\text { de algum esquema, etc. } \\
\text { - Professor omnisciente } \\
\text { - Aluno copista. }\end{array}$ \\
\hline $\begin{array}{l}\text { Descoberta guiada } \\
\text { Semidirigida } \\
\text { Descoberta dirigida } \\
\text { Observação dirigida } \\
\text { Itinerário didáctico }\end{array}$ & $\begin{array}{l}\text { Com guião } \\
\text { Sem guião }\end{array}$ & $\begin{array}{l}\text { - Os alunos são protagonistas, orientados pelo } \\
\text { professor. Segue-se um percurso pré- } \\
\text { estabelecido, em que todas as actividades são } \\
\text { guiadas sequencialmente pelo professor ou pelo } \\
\text { guião. } \\
\text { - Professor definidor de regras e sintetizador. } \\
\text { - Aluno investigador dirigido. }\end{array}$ \\
\hline $\begin{array}{l}\text { Aberta } \\
\text { Não dirigida } \\
\text { Investigativa } \\
\text { Delineamento/propo } \\
\text { problemas } \\
\text { Resolução de probler }\end{array}$ & & $\begin{array}{l}\text { - Centrada nos alunos. Estes participam na } \\
\text { planificação e desenvolvimento da actividade. } \\
\text { Saídas integradas na investigação escolar. Não } \\
\text { se conhecem, a priori, os resultados que podem } \\
\text { obter-se. } \\
\text { - Professor orientador. } \\
\text { - Aluno investigador. }\end{array}$ \\
\hline
\end{tabular}

Figura 2. Nomenclaturas mais utilizadas para tipos de atividades de campo, em função da relação estabelecida entre professor e aluno. Fonte: Adaptado de Morcillo et al. (1998)

a desenvolver para que o seu envolvimento emocional permita um bom aproveitamento da mesma (Schulz 2004). Posteriormente, e no caso de um elevado número de alunos por turma, o desejável é dividi-los por grupos, sendo que cada um deles deve ficar com alunos que possuam diferentes níveis de desempenho. Assim, pretende-se que os alunos definam, por grupo, um conjunto de hipóteses que devem ser comprovadas com a saída, assim como o material necessário. A fase seguinte é a saída de campo propriamente dita, na qual os estudantes terão que recolher a informação que considerarem mais relevante e pertinente para a verificação das hipóteses inicialmente lançadas e seguindo a orientação do guião. Após a realização da saída, os alunos terão que tratar a informação obtida e desenvolver os meios necessários à comunicação oral e escrita das suas conclusões aos restantes colegas. A última fase é a avaliação onde devem ser desenvolvidos os instrumentos que o docente considerar pertinentes e ajustados para proceder à avaliação dos conhecimentos apreendidos pelos alunos. As saídas de campo mostram, muitas vezes, a utilidade do saber científico, através de uma aprendizagem significativa. Dando o conhecimento científico através de exemplos do quotidiano tornamos as aprendizagens mais próximas e acessíveis. Ao colocarmos o aluno perante o objeto de estudo trabalhamos a aprendizagem por descoberta. Outra das vantagens é a possibilidade da existência de inter e transdisciplinaridade, originando uma transferência de conhecimentos. Numa mesma saída de campo devem ser contempladas várias áreas do conhecimento. Para além dos conteúdos específicos, uma atividade de campo permite também estreitar as relações de estima entre o professor e os alunos, favorecendo o companheirismo que resulta das experiências em comum e da convivência agradável (Viveiro et. al. 2009).

Quando nos referimos às atividades de campo no ensino das Geociências reportamo-nos à ideia de uma estratégia de ensino em que se substitui a sala de aula por outro ambiente natural ou não, onde existam condições para estudar as relações entre os seres vivos ali presentes, incluindo a interação do Homem nesse espaço, explorando os aspetos naturais, sociais, históricos, culturais entre outros.

Este estudo iniciou-se pela caraterização dos conhecimentos de um grupo de crianças, seguindo-se a projeção da ação - construção e validação de um recurso didático outdoor.

\section{Metodologia}

Neste estudo aplicámos a metodologia da investigação-ação (IA). Esta metodologia procura fundamentalmente analisar a realidade educativa específica e estimular a tomada de decisão dos seus agentes para a mudança educativa, o que implica a tomada de consciência de cada um dos intervenientes (individualmente e do grupo) de que emerge a construção de conhecimento através do confronto e contraste dos significados produzidos pela reflexão (Mesquita-Pires 2010). Através da ação pedagógica podem-se, assim, produzir dois tipos de conhecimentos específicos: a) Um conhecimento de tipo socio antropológico sobre o grupo de indivíduos com que se trabalha; b) Outro de natureza educacional, construído a partir do primeiro, mas que resulta de um cruzamento e contributos das didáticas de diferentes disciplinas (Cortesão \& Stoer, 1997).

\begin{tabular}{c|c|c|c|c|c}
\hline (C) Terrae Didat. & Campinas, SP & v.14 & n.3 & p. 477-486 & out./dez. 2018 \\
\hline
\end{tabular}




\subsection{Amostra}

O público da nossa amostra foram os alunos de $4^{\circ}$ ano de escolaridade do Agrupamento de Escolas de Celorico da Beira, envolvendo um total de 58 alunos de todo o Concelho. O preenchimento dos questionários foi anónimo e aplicado aos alunos de 2 escolas da vila de Celorico da Beira e a 8 escolas das aldeias envolventes. Analisámos os dados recolhidos e respeitámos sempre a forma em que foram registados ou transcritos.

\subsection{Instrumento de análise: 0 questionário}

Assim, optámos por elaborar um questionário (Fig. 3), recorrendo à escala de Lickert, que nos possibilitou a recolha e tratamento de informação relativa aos conhecimentos dos alunos sobre este recurso natural do meio próximo à escola. Os questionários são uma metodologia importante utilizada, pois segundo Silva (2004), o questionário é um dos instrumentos de recolha de dados utilizado nos estudos descritivos. Os dados descritivos possibilitam investigar pormenorizadamente a situação e não permitem que nenhum detalhe escape ao escrutínio. Com o questionário pretendíamos saber quais os conhecimentos que os alunos têm do Rio Zêzere como se pode observar pelo quadro que se segue:

\section{Resultados e Discussão}

\section{Amostra}

No que diz respeito à nossa amostra, constatámos que o nível etário dos alunos está compreendido entre os 8 e os 10 anos, sendo que a sua distribuição por sexos é homogénea. Tendo em atenção a caraterização dos alunos constatámos que a idade dos pais se encontra no intervalo entre os 30 e os 57 anos para o sexo masculino e no que respeita ao sexo feminino as idades variam entre os 28 e os 50 anos. Salientamos o facto de que o intervalo de idades entre os 35 - 40 anos é aquele que apresenta o maior número de mães e pais. No que respeita ao seu grau de instrução observámos que apresenta uma distribuição homogénea sendo que a maioria possui apenas o ensino primário. Só $10 \%$ dos pais tem formação superior. Em relação à situação profissional a maioria dos pais encontra-se empregado e com profissões muito variadas sendo de realçar que o nível de desemprego é bastante baixo.

\subsection{Questionário}

Após a aplicação dos questionários procedemos ao seu tratamento estatístico. Assim no que se refere à questão: “Conheces o rio Zêzere?”, 52\% dos alunos respondeu que não, não havendo diferença estatística. Quanto às questões: "Sabes onde nasce o rio Zêzere" e "Sabes onde desagua o rio Zêzere", os alunos responderam de forma semelhante, em que a resposta não é substancialmente superior à resposta sim.

Sendo assim, concluímos que sensivelmente $50 \%$ dos alunos não sabe onde nasce o rio Zêzere nem onde desagua, e $50 \%$ responde positivamente a esta questão. Este resultado é bastante interessante, na medida em que o conhecimento da sua existência pode dever-se ao facto deste ser um dos conteúdos abordado no $4^{\circ}$ ano e este rio ser um rio que fica localizado no mesmo distrito em que os alunos, da amostra, habitam.

Quanto aos aspetos relacionados com a fauna e flora a distribuição das respostas foi mais hete-

\begin{tabular}{|l|l|}
\hline Questões & O que se pretende \\
\hline Conheces o rio Zêzere & $\begin{array}{l}\text { Saber se os alunos conheciam o rio que existe no } \\
\text { local que habitam }\end{array}$ \\
\hline Sabes onde nasce o rio Zêzere & $\begin{array}{l}\text { Saber se os alunos sabiam reconhecer quer a } \\
\text { nascente quer a foz do rio }\end{array}$ \\
\hline Sabes onde desagua o rio Zêzere & $\begin{array}{l}\text { Saber se conheciam as espécies animais que } \\
\text { acompanham o rio }\end{array}$ \\
\hline $\begin{array}{l}\text { Zêzere } \\
\text { Zêzere? as espécies de fauna do rio }\end{array}$ & $\begin{array}{l}\text { Saber se conheciam as espécies vegetais que } \\
\text { existem na área circundante ao rio }\end{array}$ \\
\hline $\begin{array}{l}\text { A poluição é perigosa para os ríos? } \\
\text { A presevação deberá ser uma preocupação } \\
\text { de todos nós? }\end{array}$ & $\begin{array}{l}\text { Saber se os alunos tinham consciencia que a } \\
\text { poluição era também prejucial para os ríos. } \\
\text { ambiental. }\end{array}$ \\
\hline $\begin{array}{l}\text { Tudo o que fazemos hoje em dia prejudica teriam alguma consciencia } \\
\text { o ambiente? }\end{array}$ & $\begin{array}{l}\text { Saber se os alunos já teriam alguma consciencia } \\
\text { ambiental. }\end{array}$ \\
\hline $\begin{array}{l}\text { É importante que existam reservas e } \\
\text { parques naturais para a preservação do } \\
\text { equilíbrio entre a Natureza e a Sociedade }\end{array}$ & $\begin{array}{l}\text { Saber se os alunos já teriam alguma consciencia } \\
\text { ambiental. }\end{array}$ \\
\hline
\end{tabular}

Figura 3. Questões do questionário e os seus objetivos. Fonte Ana Farinha 
rogénea. No que respeita à questão: "Conheces as espécies de fauna do rio Zêzere?”, 83 \% responderam que não e $17 \%$ responderam que sim. Em relação à questão: "Conheces as espécies de flora do rio Zêzere?”, 90\% responderam que não e 10\% responderam que sim. Estes resultados demonstram que apesar de metade da amostra conhecer o rio, o que se encontra ao pé dele, fauna e flora, é-lhes completamente alheio, isto é, há desconhecimento da biodiversidade do rio, que aproximadamente $50 \%$ dos alunos diz conhecer.

Já no que se refere à questão respeitante à poluição, os alunos responderam quase por maioria, como se pode observar na Figura 4, que a poluição dos rios é perigosa para a sua fauna e flora, o que demonstra que já apresentam alguma consciência ambiental.

Os alunos inquiridos concordam, quase na totalidade, que é importante que existam reservas e parques naturais para a preservação do equilíbrio entre a Natureza e a Sociedade. De realçar que esta consciência ambiental poderá estar relacionada com o facto de este ser um dos conteúdos curriculares do Programa do "Estudo do Meio"do ensino primário.

Em termos de síntese da leitura dos resultados podemos afirmar que foram reveladores da consciência ambiental que os alunos detêm e da sua sensibilidade para as práticas que contribuem para a melhoria e defesa do ambiente.

Verificou-se que os alunos têm algum conhecimento da existência do rio Zêzere, mas não sabem onde nasce nem onde desagua e também não têm conhecimento sobre a sua fauna e flora. Admitem que a poluição dos rios é perigosa para as espécies de fauna e flora, assim como a preocupação que existe quer pelo Homem, quer pelas reservas e parques naturais, na preservação do ambiente e tudo o que é prejudicial à natureza.

Decorrente destes resultados, surgiu a necessidade de implementar uma prática de acordo com o tema escolhido: "Estudo do Rio Zêzere - Fauna e Flora" para assim colmatar as deficiências encontradas no conhecimento do Rio. Por conseguinte, após o estudo teórico do Rio Zêzere e dando continuidade ao trabalho foi preparada uma atividade outdoor, em função das respostas ao questionário. Para isso, foi elaborado um guião direcionado para a atividade a partir do ambiente, com o objetivo de os alunos contactarem diretamente com este rio, a sua fauna e flora envolvente, bem como a necessidade da sua preservação.

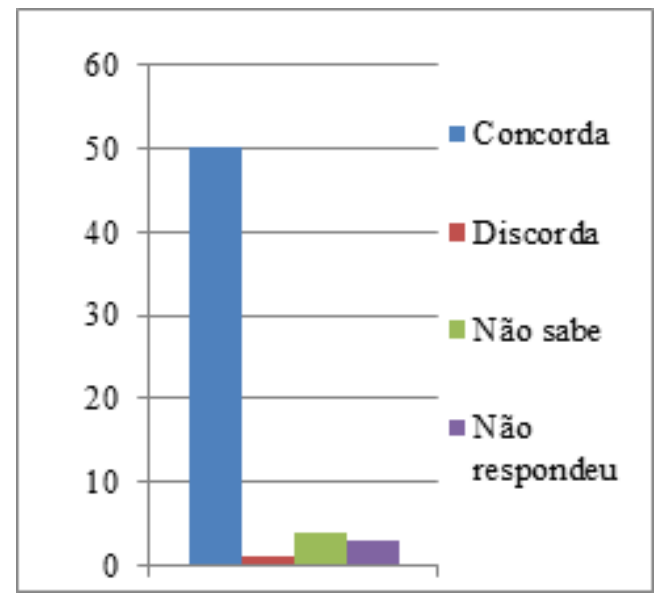

Figura 4. A poluição dos rios é perigosa para a sua fauna e flora. Fonte Ana Farinha

\subsection{Guião de outdoor}

O guião de atividades foi idealizado a partir dos resultados obtidos dos questionários aplicados aos alunos da nossa amostra. Foi aplicado e validado com um pequeno grupo de alunos para ser utilizado, futuramente, pelos alunos da escola que o queiram realizar. Atendendo a essa questão e a partir do percurso selecionado, desenvolveram-se atividades tais como o estudo das recolhas efetuados ao longo da caminhada (pequenas rochas, plantas, solo, águas, fotografias e trutas), elaboração de herbários assim como a dissecação de uma truta. Estes materiais recolhidos durante a atividade outdoor serão explorados em contexto de sala de aula. O percurso apresentado no roteiro foi anteriormente estudado e pormenorizadamente percorrido a fim de que não surjam perigos e contratempos que dificultem a sua concretização. Cada aluno, para realizar o percurso selecionado terá, antecipadamente, uma lista do material a levar e no dia da caminhada o roteiro com o percurso a efetuar.

O local escolhido foi o Rio Zêzere, este é um Rio de Portugal que se localiza em pleno Parque Natural da Serra da Estrela. Dada a importância regional, para o Concelho de Celorico da Beira, foi este o alvo do nosso estudo. Um dos objetivos deste estudo perspetivou a melhoria das práticas pedagógicas, numa lógica de observação ação. Ao longo de todo o percurso, através do diálogo orientado, os alunos são sensibilizados para a necessidade de preservar e valorizar este património natural que não se encontra poluído. O trajeto terá três locais com o apoio de diferentes materiais de recolha: o primeiro local é o de saída - Covão da Ametade (Fig. 5), parando na Fonte de Paulo Martins e numa casa típica da Serra, onde se recolhem amos- 


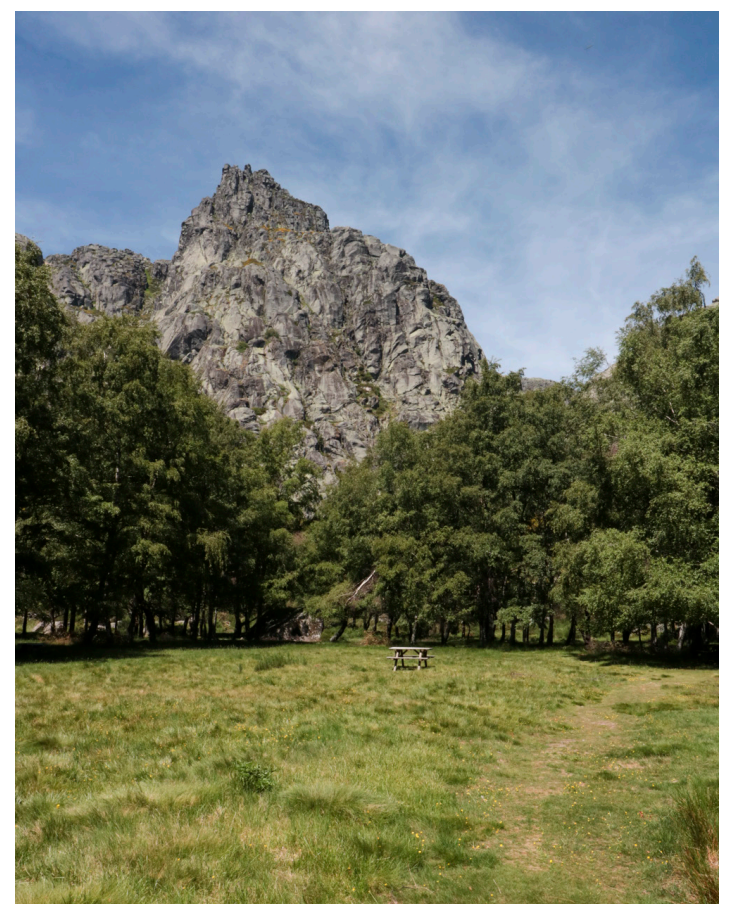

Figura 5. Covão da Ametade. Fonte Filipe Patrocínio

tras de solos, rochas e de plantas. Estas atividades encontram-se incorporadas no guião de atividades.

O segundo local é o cruzamento dos Amigos da Serra da Estrela (ASE) (Fig. 6), neste local realizam-se diversas atividades.

As atividades aqui realizadas são as seguintes:

a) elaboração de um herbário natural com as espécies de flora recolhidas e posteriormente um herbário digital

Um herbário (Fig. 7) é uma coleção científica com amostras de plantas secas, retiradas de diferentes ecossistemas de onde se extrai, utiliza e adiciona informação sobre cada uma das espécies conhecidas e sobre novas espécies de plantas, servindo como registo e referência sobre a vegetação e flora de uma determinada região, sendo dispostas segundo uma determinada ordem e disponíveis para referência ou estudo. O objetivo geral da construção de um herbário é a colheita e conservação de exemplares de plantas com as respetivas etiquetas. Nestas etiquetas são referidos os elementos respeitantes ao local e data da colheita, nome do coletor e a identificação da espécie em questão. Identificar uma planta significa descobrir o seu nome científico e a família à qual esta espécie pertence.

b) identificação do tipo das rochas recolhidas

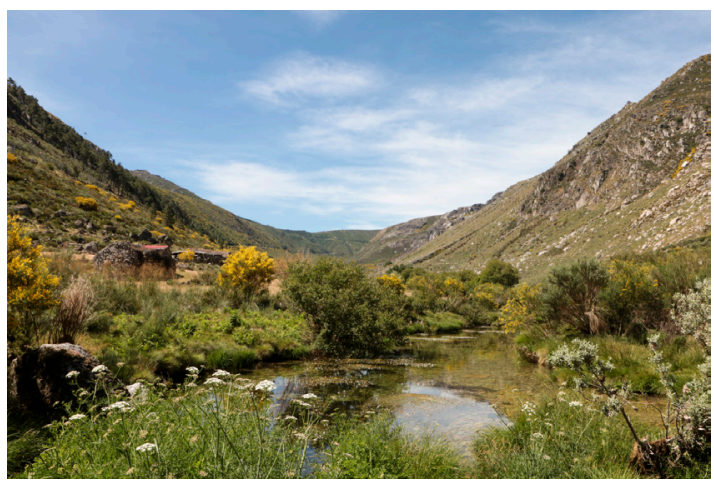

Figura 6. Cruzamento dos Amigos da Serra. Fonte Filipe Patrocínio

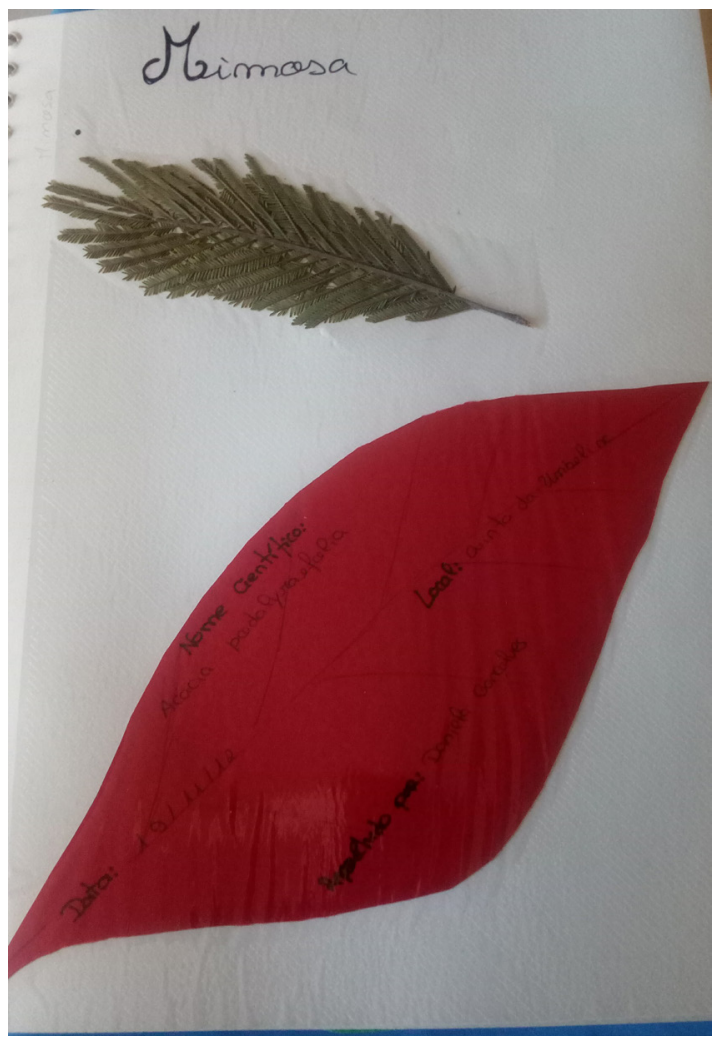

Figura 7. Exemplo de uma parte do herbário realizado pelos alunos na sala de aula. Fonte Ana Farinha

Para a identificação das amostras das rochas recolhidas propomos a observação das suas propriedades partir da utilização de materiais específicos tais como as fichas de identificação que existem na bibliografia e que colocamos de seguida como exemplo (Fig. 8):

c) análise do solo recolhido (seres vivos, vertebrados e invertebrados, permeabilidade e impermeabilidade) 


\begin{tabular}{|c|c|c|}
\hline \multicolumn{3}{|c|}{ Chave dicotómica de identificação de rochas } \\
\hline Entrada & Característica & Saída/Nome da Rocha \\
\hline \multirow{2}{*}{1} & Rocha constituída por elementos soltos & Areia ou cascalho \\
\hline & Rocha constituída por elementos unidos & Segue para 2 \\
\hline \multirow{2}{*}{2} & Rocha com aspeto laminado & Xisto \\
\hline & Rocha com aspeto não laminado & Segue para 3 \\
\hline \multirow{2}{*}{3} & Rocha cheirando a barro quando bafejada & Segue para 4 \\
\hline & Rocha não cheirando a barro quando bafejada & Segue para 5 \\
\hline \multirow{2}{*}{4} & Rocha fazendo efervescência com os ácidos & Marga \\
\hline & Rocha não fazendo efervescência com os ácidos & Argila \\
\hline \multirow{2}{*}{5} & Rocha fazendo efervescência com os ácidos & Segue para 6 \\
\hline & Rocha não fazendo efervescência com os ácidos & Segue para 7 \\
\hline \multirow{2}{*}{6} & Rocha com aspeto compacto (sem cristais) & Calcário \\
\hline & Rocha com cristais visiveis & Mármore \\
\hline \multirow{2}{*}{7} & Rocha de cor clara, constituída por minerais distintos & Granito \\
\hline & Rocha de cor escura, constituida por minerais distintos & Gabro \\
\hline
\end{tabular}

Figura 8. Chave dicotómica. Fonte Eduarda Roque et al.

Com a amostra de solo recolhida pretendemos elaborar uma análise laboratorial simples no que respeita à pesquisa de seres vivos vertebrados e invertebrados, permeabilidade e impermeabilidade, porosidade e a humidade existente no solo circundante ao rio Zêzere na área proposta percorrida pelos alunos durante a aula de campo. A análise será posteriormente realizada na sala de aula.

\section{Ficha de análise do solo recolhido}

Material recolhido - Amostra de solo Na sala de aula os alunos devem:

- Observar a amostra de solo recolhido com a ajuda da tabela auxiliar de caraterização dos solos, dar-lhe um número e preencher a etiqueta para identificação;

- Verter o conteúdo da amostra de solo para uma folha de papel;

- Observar a amostra com a lupa para identificar os diferentes elementos: seres vivos vertebrados e invertebrados e seres não vivos;

- Passar um bocado do solo entre o polegar e $\mathrm{o}$ indicador para sentir a textura, o grão e o cheiro;

- Deitar uma parte da amostra num funil feito a partir de uma metade de uma garrafa de água de plástico. Este funil deve estar forrado com papel de filtro. Colocar o funil dentro da outra metade da garrafa. Depois deitar uma quantidade de água (igual para todas as amostras recolhidas);

- Cronometrar o tempo que leva a água a passar em cada tipo de amostra diferente. O solo será tanto mais permeável quanto mais rápido deixar passar a água;

- Preencher a ficha de registo, medindo e pesando os elementos naturais (não vivos e vivos) e artificiais. A dimensão poderá ser avaliada com a utilização de fita métrica ou de peneiras (a que será atribuída uma escala, por exemplo $1,2$ e 3$)$.

Por último o terceiro local é o de chegada Viveiro das Trutas (Fig. 9) nas Caldas de Manteigas, onde terminam a realização das atividades. Neste local do Parque Natural da Serra da Estrela é enfatizada a relação entre a qualidade da água do rio e a existência das trutas, pois este peixe é muito sensível à poluição. Mais uma vez, os alunos são envolvidos na importância da preservação dos recursos da natureza.

Neste ponto como se tem o viveiro das trutas, é disponibilizada uma truta para posterior análise em sala de aula: 


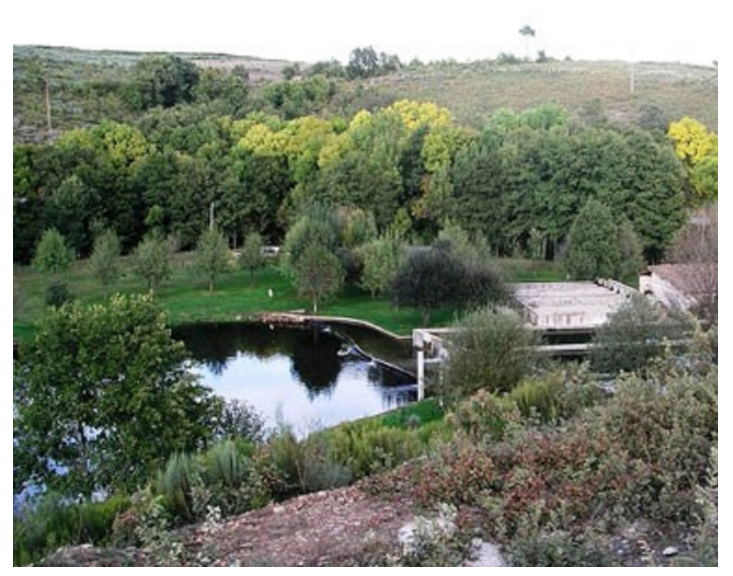

Figura 9. Viveiro das trutas. Foto Ana Farinha

\section{d) dissecação de uma truta}

Este trabalho tem como objetivo realizar uma abordagem simples acerca da morfologia de um peixe, destinada aos alunos do $4^{\circ}$ ano do ensino primário. Apesar de não fazer parte integrante do programa do $4^{\circ}$ ano de escolaridade podemos adaptar como sendo o aprofundar dos conhecimentos da Natureza, proporcionando os instrumentos e as técnicas necessárias para que os alunos possam construir o próprio saber. Segundo a Organização Curricular e Programas do ensino primário, será através de situações diversificadas de aprendizagem que incluam o contacto direto com o meio envolvente, da realização de pequenas investigações e experiências reais na escola e na comunidade, bem como através do aproveitamento da informação vinda de meios mais longínquos, que os alunos irão apreendendo e integrando, progressivamente o significado dos conceitos (2006).

Após a recolha dos materiais ao longo do percurso, e sua primeira análise, a sua análise completa é realizada em sala de aula como anteriormente foi referido. À medida que serão realizadas as várias atividades irá sendo elaborado um glossário. A elaboração deste glossário foi com o propósito de se criar um dicionário de termos técnicos organizados por assuntos alfabeticamente. Este glossário proposto como sugestão de atividades a trabalhar na sala de aula, irá proporcionar aos alunos as explicações de conceitos relevantes que vão surgindo relacionados com a fauna e a flora do rio Zêzere, quer a nível prático durante a aula de campo, quer a nível teórico na parte investigativa pelos alunos na sala de aula. A sua elaboração irá ser realizada através de dicionários interligando as novas tecnologias no ensino das ciências.

\section{Conclusões}

Ser professor é um desafio constante. Perspetivamos a formação pedagógica destes profissionais num contexto IA, abordando a ação educativa como uma ação profundamente humana visando o desenvolvimento integral dos alunos, nas dimensões pessoal e de cidadania. O desenvolvimento de práticas de educação ambiental possibilita ao professor a oportunidade de contribuir para a construção de uma nova ética sobre o meio, favorecendo e potenciando nos alunos o desenvolvimento e interiorização de valores e atitudes ecocêntricas que lhes sirvam de referência ao longo da vida. Os resultados deste estudo mostram que os alunos possuem consciência ambiental e estão sensibilizados para as consequências da poluição de um modo geral. Contudo, apesar de afirmarem conhecer o Rio Zêzere, não sabem onde nasce nem onde desagua, nem têm conhecimento sobre a sua fauna e flora. Estes resultados levantam interrogações interessantes sobre as práticas de ensino e aprendizagem, que foram desenvolvidas aquando da lecionação dos conteúdos curriculares (aspetos físicos do meio local), em sala de aula. Cabe ao professor proporcionar aos alunos novos instrumentos e novas técnicas, despertando por um lado a sua curiosidade pelo meio natural próximo e, por outro lado, interligar as aprendizagens à noção de responsabilidade perante o ambiente próximo. Importa que os conteúdos curriculares de Geociências sejam ensinados, tanto quanto possível, interligados à realidade próxima das crianças e ensinados com a preocupação de desenvolver atitudes de preservação e proteção do meio natural. As atividades outdoor pretendem proporcionar um aumento da preocupação perante o ambiente assim como desenvolver comportamentos relevantes perante o ambiente e ainda reduzir o impacto da ação humana na natureza (Bogner \& Wiseman 2004).

Podemos então afirmar que a atividade outdoor surge como uma forma enriquecedora do processo de ensino e aprendizagem em ambiente formal de sala de aula. Não obstante a pertinência destes aspetos, saliente-se, ainda, a importância das atividades outdoor como forma de dar relevo a problemas ambientais e capaz de auxiliar o aluno na construção do conhecimento científico (Salvador \& Vasconcelos 2007). As atividades outdoor constituem metodologias de ensino de grande potencialidade didática no ensino primário. Um programa outdoor bem planeado pode auxiliar e ajudar os alunos 
e professores de uma forma a facilitar a interação entre eles e possibilita situações de inserção onde o conhecimento proveniente de sala de aula é útil e essencial (Bieberbach 2013). Naturalmente, o fator tempo poderá constituir um aspeto limitante para a implementação de atividades outdoor, pois estas necessitam de um contínuo de exploração dos recursos e conteúdos curriculares associados, após a saída. A limitação é mais significativa quando os alunos são crianças da educação primária, exigindo do professor um conhecimento didático atual imprescindível à adequação das práticas de ensino. Face aos graves problemas ambientais da biosfera, a educação ambiental torna-se cada vez mais uma área em que as atividades outdoor constituem metodologias com potencialidades adequadas às aprendizagens promotoras de atitudes, valores $\mathrm{e}$ capacidades de intervenção ecocêntricas e também se enquadra nos projetos das escolas desenvolvendo-se um trabalho de equipa no qual todas as áreas curriculares podem ser trabalhadas.

\section{Referências}

Bierbebach G.T.R. 2013. Educação outdoor: uma "ferramenta" no ensino de ciencias e biología. Curitiba: Univ. Fed. Paraná. 38p. (Monogr.).

Bogner F.X., Wiseman M. 2004. Outdoor ecology education and pupils' environmental perception in preservation and utilization. Sci. Educ. Intern., 15(1):27-48.

Carbonell J.A. 2002. Aventura de Inovar a Mudança na Escola. Porto Alegre: Artmed. 144p. (Col. Inovação Pedagógica).

Caride J.A., Meira P.Á. 2004. Educação Ambiental e Desenvolvimento Humano. Lisboa: Horizontes Pedagógicos. 302p.

Cortesão L., Stoer S. 1997. Investigação-acção e a produção de conhecimento no âmbito de uma formação de professores para a educação inter/multicultural. Educação, Sociedade \& Culturas, 7:7-28.

Cruz S.G.M. 2007. A Importância da Educação Ambiental no $1^{\circ}$ Ciclo do Ensino Básico: Um Estudo de caso. Porto: Universidade Portucalense Infante D. Henrique. 267p. (Dissert. Mestrado).

Dourado L., Leite L. 2008. Actividades laboratoriais e o ensino de fenómenos geológicos. In: Congreso de ENCIGA, 21, Ourense. Anais... Carballiño: IES Manuel Chamoso Lamas. (CD-ROM).

Farinha A.D. 2012. Relatório de Prática de Ensino Supervisionada do curso de Mestrado Educação Pré-Escolar e Ensino do $1^{\circ}$ Ciclo do Ensino Básico. Inst. Politécn. Guarda. Escola Superior de Educação, Comunicação e Desporto. Guarda. 118p. (Dissert. Mestrado).

Ferreira M.E., Antão A.M. 2000. A Diversidade na Biosfera (Ciências da Natureza $5^{\circ}$ Ano). Lisboa: Plátano. 159p.
Leite L. 2000. O trabalho laboratorial e a avaliação das aprendizagens dos alunos. In: Sequeira M., Dourado L., Vilaça M.T., Silva J.L., Afonso A.S., Baptista J.M. orgs. 2000. Trabalho prático e experimental na educação em Ciência. Braga, Univ. Minho. p.91108.

Mesquita-Pires C. 2010. A Investigação como suporte ao desenvolvimento profissional docente. EER: Revista de Educação, 2(2):66-83.

Ministério da Educação 2000. Currículo Nacional do Ensino Básico Competências Essenciais. DEB. Lisboa: Portugal. 227p.

Morcillo J., Rodrigo M. et al. 1998. Caracterización de las prácticas de campo: justificación y primeiros resultados de una encuesta el profesorado. Enseñanza de las Ciencias de la Tierra. 6(3):242-250.

Morin E. 1991. Introdução ao Pensamento Complexo. Lisboa: Instituto Piaget. 177p.

Orion N. 2001. A educação em Ciências da Terra. Da teoria à prática-implemantação de novas estratégias de ensino em diferentes ambientes de aprendizagem. In: Marques L., Praia J. orgs. 2001. Geociências nos currículos dos ensinos básico e secundário. Aveiro: Univ. Aveiro. p. 93-114.

Palma M.I.M. 2005. Educação Ambiental: a Formal e a Não Formal. Contributos dos Centros de Recursos de Educação Ambiental para a Formação das Crianças do $1^{\circ}$ Ciclo do Ensino Básico. Braga, Univ. Minho. Inst. Estudos da Criança. 271p. (Dissert. Mestrado).

Priest S. 1986. Redefining Outdoor Education: A Matter of Many Relationships". J. Environ. Educ., 19:s/1.

Salvador P.M.P.D. 2002. Avaliação do Impacte de Actividades de Outdoor. Contributo dos Clubes de Ciências para a Alfabetização Científica. Porto, Fac. Ciências, Univ. Porto. 214p. (Dissert. Mestrado).

Salvador P.,Vasconcelos C.M.S. 2007. Actividades outdoor e a alfabetização científica de alunos de um clube de ciencias. Florianópolis, Linhas, 8(2):7690.

Santos V.M.N., Compiani M. 2005. Formação de professores: desenvolvimento de projectos escolares de educação ambiental com outro integrado de recursos de sensoriamento de trabalhos de campo para o estudo do meio ambiente e exercício de cidadania. In: Enc. Nac. Pesq. Educ. Ciências, 5, ABRAPEC, Bauru. Anais... ABRAPEC.

Schulz C.M. 2004. Você tem muito o que aprender, Charlie Brown! São Paulo: Conrad Editora do Brasil. 127p.

Silva A.A.T. 2004. Ensinar e aprender com as Tecnologias. Um estudo sobre as atitudes, formação, condições de equipamento e utilização nas escolas do $1^{\circ} \mathrm{Ci}$ clo do Ensino Básico do Concelho de Cabeceiras de Basto. Braga, Univ. Minho. Inst. Educ. e Psicologia. 262p. (Dissert. Mestrado).

Viveiro A.A., Diniz R.E.S. 2009. Atividades de campo no ensino das ciências e na educação ambiental: refletindo sobre as potencialidades desta estratégia na prática escolar. Ciência em Tela, 2(1):s/p.

Zabalza M.B. 2000. O discurso didáctico sobre atitudes e valores no ensino. Lisboa: Inst. Piaget. 306p. 